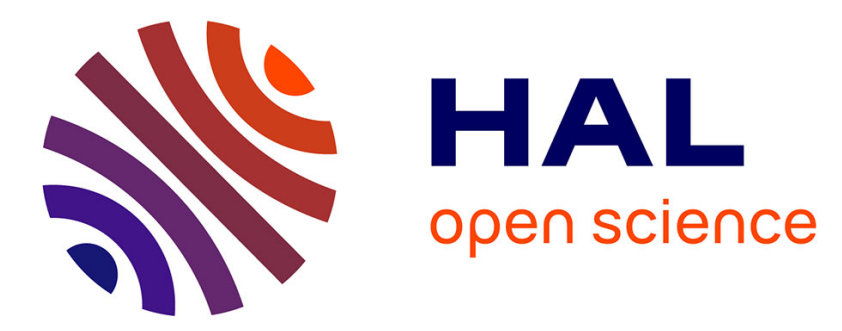

\title{
Long-Range Antenna Systems for In-Body Biotelemetry: Design Methodology and Characterization Approach
}

\author{
Denys Nikolayev, Maxim Zhadobov, Karban Pavel, Ronan Sauleau
}

\section{To cite this version:}

Denys Nikolayev, Maxim Zhadobov, Karban Pavel, Ronan Sauleau. Long-Range Antenna Systems for In-Body Biotelemetry: Design Methodology and Characterization Approach. EMBEC \& NBC 2017, Jun 2017, Tampere, Finland. pp.233-236, 10.1007/978-981-10-5122-7_59 . hal-01561080

HAL Id: hal-01561080

https://hal-univ-rennes1.archives-ouvertes.fr/hal-01561080

Submitted on 12 Jul 2017

HAL is a multi-disciplinary open access archive for the deposit and dissemination of scientific research documents, whether they are published or not. The documents may come from teaching and research institutions in France or abroad, or from public or private research centers.
L'archive ouverte pluridisciplinaire HAL, est destinée au dépôt et à la diffusion de documents scientifiques de niveau recherche, publiés ou non, émanant des établissements d'enseignement et de recherche français ou étrangers, des laboratoires publics ou privés. 


\title{
Long-Range Antenna Systems for In-Body Biotelemetry: Design Methodology and Characterization Approach
}

\author{
Denys Nikolayev ${ }^{1,2}$, Maxim Zhadobov ${ }^{1}$, Pavel Karban² and Ronan Sauleau ${ }^{1}$ \\ ${ }^{1}$ Institute of Electronics and Telecommunications of Rennes (IETR), University of Rennes 1, Rennes, France \\ ${ }^{2}$ Regional Innovation Centre for Electrical Engineering (RICE), University of West Bohemia, Pilsen, Czechia
}

\begin{abstract}
Long-range in-body biomedical telemetry enables monitoring of physiological parameters while maintaining mobility and freedom of movement. This emerging technology creates new applications in medicine, clinical research, wellness, and defense. Current in-body biotelemetry devices operate within about a meter around a user that limits their applicability. Here we examine the variety of approaches that, combined, can significantly extend the operating range. The radiation efficiency is constrained by attenuation and reflection losses in tissues. First, choosing an optimal operating frequency can minimize the losses. A specific antenna design is then required to decouple the antenna from a body. Two successful antenna design approaches are reviewed: (1) using loop antennas and (2) dielectrically loaded microstrip antennas. On-body matching layers and repeaters can be used to further improve power transmission. Finally, we present the radiation characterization method for in-body antennas in spherical phantoms with a direct illumination technique using an analog fiber optic link.
\end{abstract}

Keywords—biomedical telemetry, implantable antennas, inbody, ingestible antennas, miniature antennas.

\section{INTRODUCTION}

Implantable, ingestible and injectable (in-body) devices for biomedical telemetry can continuously monitor and yield physiological parameters while maintaining mobility and quality of life of a patient [1]. The progress in microelectromechanical systems and microfluidics along with further miniaturization of electronics and biosensors have empowered new generation of biotelemetry devices. This emerging technology created new applications in medicine, clinical research, wellness, and defense (Fig. 1). Apart from telemetering various diagnostic data (endoscopic video, temperature, pressure, $\mathrm{pH}$, glucose levels, etc.), modern in-body applications include, but are not limited to: brain-machine interfaces and visual prosthesis, pacemakers and defibrillators, drug delivery and hyperthermia [2].

Fig. 2 shows a generic flowchart of an in-body wireless device. An in-body device uses a wireless link to transmit

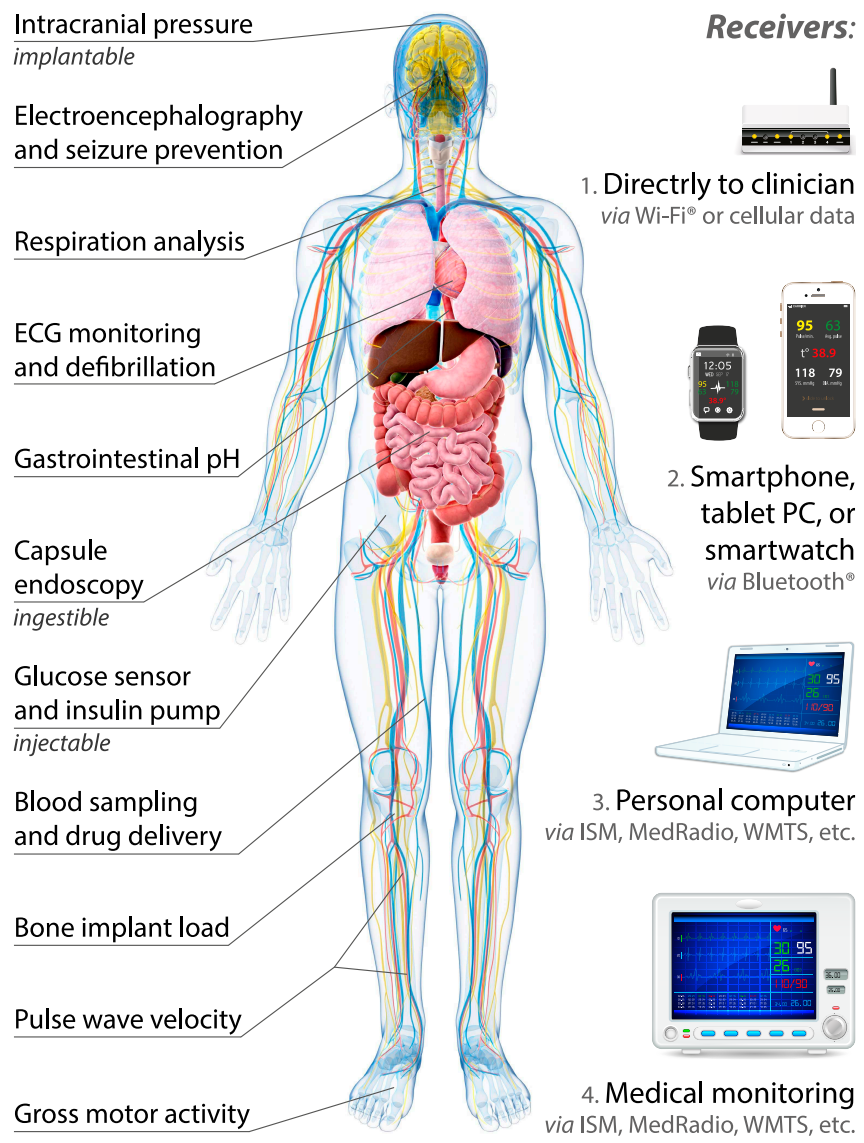

Fig. 1: left: existing and potential applications of in-body biotelemetry; right: some examples of on-and off-body receivers.

biotelemetry data or to receive or modify operational and treatment instructions. The most common solutions are radio frequency (RF) transmission, inductive coupling, and human body communication method. Each way has its own advantages and drawbacks. Yet, RF transmission in VHF-SHF bands yields the longest range and highest data transfer rates for in-body wireless devices [3]. As for the power source, a multiband RF antenna can integrate both data transmission and wireless power transfer functionality increasing the available space inside an in-body device. 
Several antennas have been reported in the last decade [49]. They can be divided into three groups: wire [4], printed on a rigid PCB [5], and conformal printed antennas [6]. The latter type makes use of the capsule surface minimizing the occupied volume. Various types of conformal designs have been reported: loop antennas [6], dipoles [7], and various microstrip antennas $[8,9]$. Comprehensive reviews can be found in $[2,10]$.

Enhancing the operating range of in-body antennas remains a major challenge as for the time being they are able to operate only up to a few meters.

\section{OPERATING RANGE EXTENSION}

When improving the operating range of an in-body device, the main issues to face are low radiation efficiency $(\eta<0.1 \%)$ and strong coupling to lossy and dispersive biological tissues.

\section{A. Operating Frequency Choice}

The radiation efficiency $\eta$ of an in-body antenna is frequency-dependent [11]. The optimal operating frequency relies on how far the antenna is from the body surface, what tissues surround it, and how electrically large is the antenna.

The most suitable unlicensed frequency bands for ingestible applications are MedRadio (Medical Device Radiocommunications Service) (401 to 406,413 to 419,426 to 432 , 438 to 444,451 to 457 ) MHz, and mid-ISM (the Industrial, Scientific and Medical) (433 to 434.8) MHz [12]. As for implantable applications, the closer the antenna is to the skin, the less the signal attenuates within the tissue. Therefore, higher frequencies can be used to avoid the limitations on the radiation efficiency $\eta$ for electrically small antennas (ESA; if the antenna electrical size $k a<0.5$, it can be considered electrically small [13]). The most efficient bands would be the ISM $2.45 \mathrm{GHz}$ for a few $\mathrm{cm}$ deep implants and $5.8 \mathrm{GHz}$ for the subcutaneous [11].

\section{B. Improving Efficiency of In-Body Antennas}

Considering the operating frequency $f_{0}$ is close to optimal, the radiation efficiency is still constrained by the attenuation and reflection losses in tissues. In addition, the required miniaturization of antennas imposes fundamental limits on achievable radiation efficiency for ESAs.

A magnetic type antenna (e.g. loop) couple less to tissue due to the magnetic component dominating in its near field. Loop antennas have a good radiation performance [6]. However, a spatial variation of tissue EM properties affects the

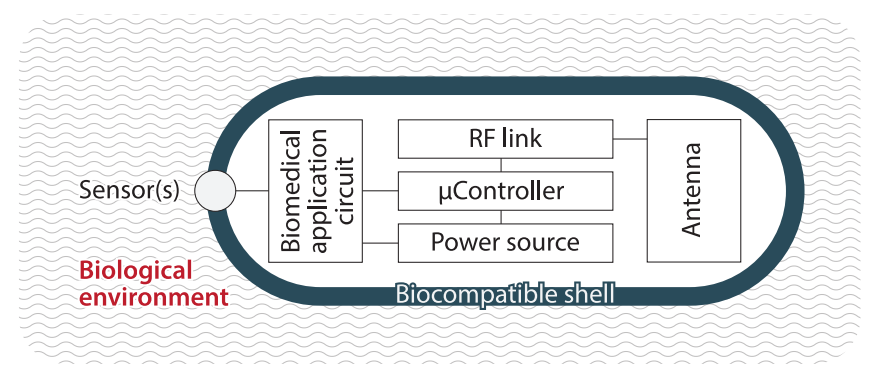

Fig. 2: Outline of an in-body capsule for biomedical telemetry.

antenna impedance and thus can deteriorate matching. Typically, to compensate for the antenna detuning, an extended bandwidth BW is preferred. However, it undermines the radiation efficiency, as $\mathrm{BW} \propto k a / \eta[13]$.

Dielectric loading increases the robustness of antennas [14] that allows reducing the necessary bandwidth and increasing the electrical size $k a$. Increased radiation efficiency has been achieved in $[9,15]$ by loading antennas with thin ceramic superstrate $(<1 \mathrm{~mm})$. High permittivity filling of the device-ideally, matched with the tissue permittivity—helps further increase $\eta$ [9]. In this way, a dielectrically loaded microstrip antenna can potentially outperform loop antennas in both the robustness and radiation performance.

\section{Matching Layers}

Merli et al. studied the effect of on-body matching layers that improve power transmission from a body [16]. An ideal matching layer (71 mm thick) can increase the power transmission for up to $8 \mathrm{~dB}$. Realistic materials (fiber, neoprene and silicon have been studied) with reasonable thickness (up to $20 \mathrm{~mm}$ ) can provide up to $2 \mathrm{~dB}$ improvement.

\section{On-Body Repeaters}

Kiourti et al. proposed a dual-band on-body repeater antenna [17]. The antenna receives a low power MedRadio signal (401-406 MHz) from an in-body implant and retransmits it using the $2.45 \mathrm{GHz}$ ISM band. This approach reduces the required implant power by a factor of 100 for achieving the same range without the repeater antenna.

Combining aforementioned approaches, a substantial improvement in operating range is achievable. Depending on the receiver antenna sensitivity and link-budget evaluation methodology, the range of $10-15 \mathrm{~m}$ is foreseeable in near future for in-body devices. Along with a repeater, this range can be further extended. 
Numerical modeling in anatomically realistic phantoms allows estimating in-body antenna path loss and gain [9]. However, an accurate evaluation of radiation performance of antennas require experimental validation.

\section{FAR-FIELD CHARACTERIZATION OF IN-BODY ANTENNAS}

Despite many reliable methods for impedance measurements, radiation characterization of both electrically and physically small antennas remains a major challenge. The antenna under test (AuT) couples strongly to a feeding cable that leads to impaired measured data [18]. The current induced on the cable may affect the radiation pattern and matching, making difficult, if not impossible, to separate the antenna radiation from the one of the cable. Different approaches allow minimizing this effect: baluns [19], differential feeding techniques [20], electrooptical converters [21], or measurements using a monostatic scattering characterization of an antenna [22]. For in-body antennas, the problem is more complicated as, in addition to these sources of error, the antenna has to be measured in a lossy phantom.

\section{A. Phantoms}

To evaluate experimentally in-body radiation performance of ingestible and implantable antennas, we submerge them in liquid phantoms with various EM properties depending on the target antenna application. To achieve the target properties, several methods exist [23, Ch. 2]. We use water-sugar-salt recipe [24]. The properties of the phantom are defined using an in-house model based on a full-factorial experiment design along with the response surface optimization methodology. The EM properties of the phantoms are characterized using SPEAG DAK kit [25].

The AuT is centered inside a glass spherical container filled with the liquid phantom. This approach is more appropriate for estimating the radiation performance of in-body antennas with undefined position within the body (for instance, ingestible) [10]. The spherical phantom preserves the intrinsic radiation pattern of the antenna whereas other shapes (e.g. cylindrical or cubic) may mislead about the antenna performance in terms of directivity.

The phantom diameter should be large enough for not to perturb the antenna impedance by the proximity of air. However, a too big phantom would strongly attenuate the signal reducing the signal-to-noise ratio and affecting the measurement accuracy. Hence, we have chosen to work with a $\varnothing 100 \mathrm{~mm}$ phantom.

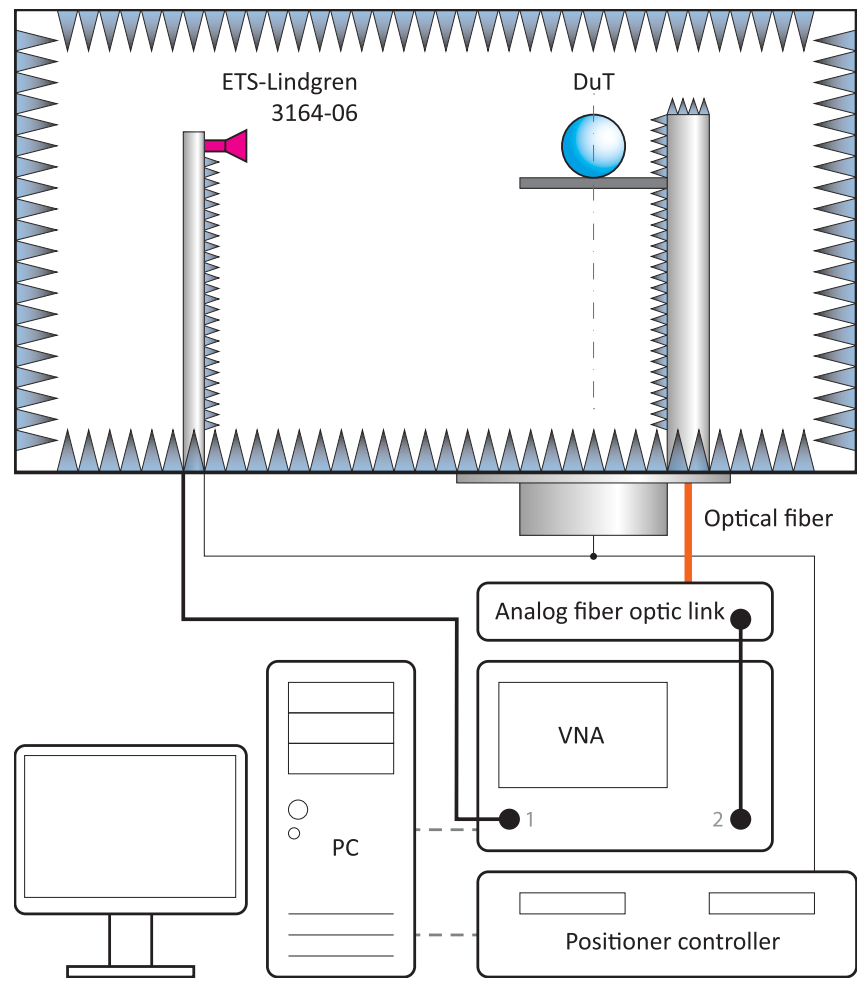

Fig. 3: The measurement setup used at IETR for characterizing radiation performance of in-body antennas.

\section{B. Measurement Setup}

We characterize in-body antennas using the direct illumination far-field technique. Fig. 3 depicts the measurement setup. A $50 \Omega$ semi-rigid coaxial cable links the antenna to an SMA connector located outside the spherical phantom container. A silicone-sealed $\varnothing 10 \mathrm{~mm}$ polyamide tube is fitted between the AuT and the connector to insulate the cable from the phantom. The vertically positioned AuT and its container constitute the device under test (DuT).

The DuT localizes at a distance from the measurement horn fulfilling the far-field criteria. An electro-optical converter (enprobe LFA-3 [26]) feeds the DuT (Fig. 3). In this way, an optical fiber replaces the RF cable inside an anechoic chamber thus minimizing the main source of signal impairment. The DuT is mounted and aligned on the tower positioner using foam blocks $\left(\varepsilon_{r} \approx 1.0, \tan \delta \approx 0.001\right)$.

The estimation of the realized gain uses the gain substitution technique employing a reference antenna of a known gain (ETS-Lindgren Model 3164-06 [27], 300 MHz-6 GHz). 


\section{CONCLUSION}

Enhancing the operating range of biotelemetry devices up to $10-15 \mathrm{~m}$ would allow to monitor physiological parameters unaffecting mobility and quality of life of a user. By combining the reviewed approaches to radiation efficiency enhancement, a substantial improvement of the range is achievable.

An accurate far-field characterization of miniature in-body antennas, however, faces many challenges. The approach proposed in this paper improves the measurement accuracy in two ways: (1) spherical phantoms preserve the intrinsic radiation pattern of an antenna; (2) replacing the majority of a feeding cable with an optical fiber as well as insulating the remaining part with air allow suppressing currents induced on the cable.

\section{CONFLICT OF INTEREST}

The authors declare that they have no conflict of interest.

\section{ACKNOWLEDGEMENTS}

This work was supported by the BodyCap Company, the French Ministry of Foreign Affairs and International Development through Eiffel Scholarship, the CNRS/DGA through PEPS program, the Ministry of Education, Youth and Sports of Czechia under the RICE-New Technologies and Concepts for Smart Industrial Systems, project No. LO1607.

\section{REFERENCES}

1. Kiourti A, Nikita K. A review of in-body biotelemetry devices: implantables, ingestibles, and injectables IEEE Trans. Biomed. Eng. 2017:in press.

2. Nikita K. Handbook of biomedical telemetry. Hoboken, NJ: John Wiley \& Sons 2014.

3. Chow E, Morris M, Irazoqui P. Implantable RF medical devices: the benefits of high-speed communication and much greater communication distances in biomedical applications IEEE Microw. Mag. 2013;14:64-73.

4. Kwak S, Chang K, Yoon Y. The helical antenna for the capsule endoscope in IEEE APS Int. Symp.;2B(Washington, DC):804-807 2005.

5. Merli F, Bolomey L, Zurcher J, Corradini G, Meurville E, Skrivervik A. Design, realization and measurements of a miniature antenna for implantable wireless communication systems IEEE Trans. Antennas Propag. 2011;59:3544-3555.

6. Alrawashdeh R, Huang Y, Kod M, Sajak A. A broadband flexible implantable loop antenna with complementary split ring resonators IEEE Antennas Wireless Propag. Lett. 2015;14:1506-1509.

7. Izdebski P, Rajagopalan H, Rahmat-Samii Y. Conformal ingestible capsule antenna: a novel chandelier meandered design IEEE Trans. Antennas Propag. 2009;57:900-909.

8. Cheng X, Senior D, Kim C, Yoon YK. A compact omnidirectional self-packaged patch antenna with complementary split-ring resonator loading for wireless endoscope applications IEEE Antennas Wireless Propag. Lett. 2011;10:1532-1535.
9. Nikolayev D, Zhadobov M, Le Coq L, Karban P, Sauleau R. Robust ultra-miniature capsule antenna for ingestible and implantable applications IEEE Trans. Antennas Propag.. 2017:in press.

10. Nikolayev D, Zhadobov M, Sauleau R, Karban P. Antennas for ingestible capsule telemetry in Advances in Body-Centric Wireless Communication: Applications and State-of-the-ArtLondon, UK: IET 2016.

11. Poon A, O’Driscoll S, Meng T. Optimal frequency for wireless power transmission into dispersive tissue IEEE Trans. Antennas Propag. 2010;58:1739-1750.

12. Chirwa L, Hammond $\mathrm{P}$, Roy S, Cumming D. Electromagnetic radiation from ingested sources in the human intestine between $150 \mathrm{MHz}$ and 1.2 GHz IEEE Trans. Biomed. Eng. 2003;50:484-492.

13. Best S, Yaghjian A. The lower bounds on $\mathrm{Q}$ for lossy electric and magnetic dipole antennas IEEE Antennas Wireless Propag. Lett. 2004;3:314-316.

14. Nikolayev D, Zhadobov M, Karban P, Sauleau R. Increasing the radiation efficiency and matching stability of in-body capsule antennas in 10th Europ conf. on anten. and propag.(Davos, Switzerland):1-5 2016.

15. Kiourti A, Nikita K. Miniature scalp-implantable antennas for telemetry in the MICS and ISM bands: design, safety considerations and link budget analysis IEEE Trans. Antennas Propag. 2012;60:3568-3575.

16. Merli F, Fuchs B, Mosig J, Skrivervik A. The effect of insulating layers on the performance of implanted antennas IEEE Trans. Antennas Propag. 2011;59:21-31.

17. Kiourti A, Costa J, Fernandes C, Nikita K. A broadband implantable and a dual-band on-body repeater antenna: design and transmission performance IEEE Trans. Antennas Propag. 2014;62:2899-2908.

18. Huitema L, Delaveaud C, D'Errico R. Impedance and radiation measurement methodology for ultra miniature antennas IEEE Trans. Antennas Propag. 2014;62:3463-3473.

19. Pivnenko S, Zhang J, Khatun A, Laitinen T, Carlsson J. Characterization of small antennas for hearing aids by several measurement techniques in 4th Europ conf. on anten. and propag.(Barcelona, Spain):1-5 2010.

20. Suzan M, Haneda K, Icheln C, Khatun A, Takizawa K. An ultrawideband conformal loop antenna for ingestible capsule endoscope system in 10th Europ conf. on anten. and propag.(Davos, Switzerland):1-5 2016.

21. Loh T, Cheadle D, Rosenfeld L. Radiation pattern measurement of a low-profile wearable antenna using an optical fibre and a solid anthropomorphic phantom Electronics. 2014;3:462-473.

22. Wiesbeck W, Heidrich E. Wide-band multiport antenna characterization by polarimetric RCS measurements IEEE Trans. Antennas Propag. 1998;46:341-350.

23. Hall P, Hao Y. Antennas and Propagation for Body-Centric Wireless Communications. Norwood, MA: Artech House 2012.

24. Karacolak T, Hood A, Topsakal E. Design of a dual-band implantable antenna and development of skin mimicking gels for continuous glucose monitoring IEEE Trans. Microw. Theory Techn. 2008;56:10011008 .

25. Schmid \& Partner Engineering AG - "Dielectric assessment kit" at http://www.speag.com/products/dak/dielectric-measurements/

26. enprobe GmbH - "LFA-3 analog fiber optic link" at http://www.enprobe.de/products_FO-Links.htm

27. ETS-Lindgren - "3164-06 open boundary quad-ridged horn" at http://www.ets-lindgren.com/3164-06

$\begin{array}{ll}\text { Author: } & \text { Denys Nikolayev } \\ \text { Institute: } & \begin{array}{l}\text { Institute of Electronics and Telecommunications of Rennes } \\ \end{array} \\ \text { UMR CNRS 6164, University of Rennes 1 } \\ \text { Street: } & \text { 263 Avenue du General Leclerc } \\ \text { City: } & \text { 35042 Rennes } \\ \text { Country: } & \text { FRANCE } \\ \text { Email: } & \text { denys.nikolayev@univ-rennes1.fr }\end{array}$

